\title{
Neurological Sequelae Following Pediatric Cardiac Interventions
}

\author{
Hala Mounir Agha ${ }^{1}$, Mai Mahmoud Hussien² ${ }^{2 *}$ Marian Y Girgis ${ }^{3}$, Omneya Gamal Eldin Afify ${ }^{3}$, Mervat Ahmed Haroun ${ }^{3}$ \\ ${ }^{1}$ Department of Pediatrics, Pediatric Cardiology Division, Specialized Pediatric Hospital, Cairo University; ${ }^{2}$ Department of \\ Pediatrics, National institute of neuromotor system, General organization of Teaching hospitals and Institutes; ${ }^{3}$ Department of \\ Pediatrics, Pediatric Neurology Division, Specialized Pediatric Hospital, Cairo University
}

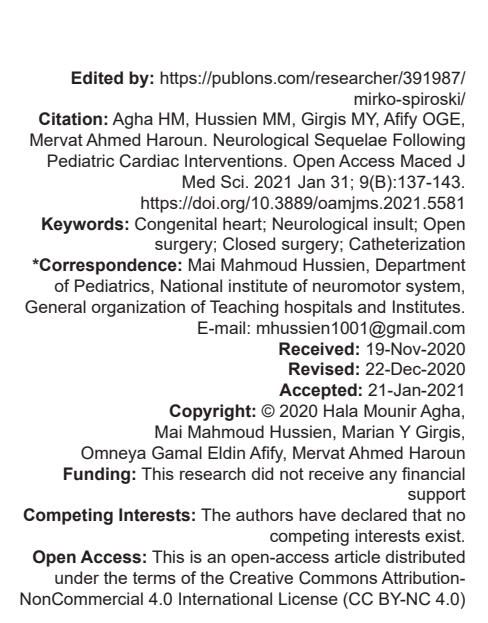

\section{Abstract}

PURPOSE: The aim of the present study was to assess neurological sequelae within 30 days of surgical or cardiac catheter interventions in infants and children.

METHOD: In this cross-sectional study, we evaluated all patients who developed neurological problems after cardiac interventions either by surgery or by catheter by clinical evaluation, brain imaging, and electrophysiological studies. RESULTS: Among 1200 procedures were performed; 895 (74.6\%) were cardiac catheterizations either diagnostic or intervention, $167(13.9 \%)$ were open-heart surgery, and $138(11.5 \%)$ were closed heart surgery. The overal incidence of post-procedure neurological dysfunction in the studied population was $3.4 \%$. The differences between the three groups were statistically significant $(p<0.0001$ (. In our series, the neurological complications were in the form of disturbed conscious level in 2/41 (4.9\%), impaired motor function in 11/41 (26.8\%), impaired mental functions in 6/41(14.6\%), hyperreflexia in $27 / 41(65.9 \%)$, and seizures in 38/41 (92.7\%). The most common presentation of seizures was in the form of focal fits $21 / 41(51.2 \%)$, followed by generalized fits in $15 / 41(36.6 \%)$ and then myoclonic fits $2 / 41(4.9 \%)$.

CONCLUSION: Seizures are the most common complication following cardiac interventions in pediatric age and the highest percentage following open heart surgery.

\section{Introduction}

Congenital heart diseases (CHDs) are one of the most common congenital defects being responsible for multitude of complications despite the recent surgical and interventional techniques improvements [1]. The mortality rate is increased in complex conditions associated with heart failure, respiratory failure, or shock. Indeed, the mortality rate reported by several centers is around $6 \%$ in children compared to $3 \%$ in adults [2].

Recent evidence suggests that recent therapeutic interventions aimed at minimizing progressive organ function deterioration, especially the brain, might be as well helpful in reducing in-hospital mortality and improving neurological outcome as well as quality of life after cardiac arrest insults [3]. Circulatory arrest during cardiac surgery is often associated with a great risk of postoperative neurological deficit with strokes in adults and seizures in children being the most common neurological complication after a cardiac surgery [4]. Early-onset seizures are common manifestation in children afflicted with arterial ischemic strokes, yet their clinical features and outcomes have been understudied [5]. Recently, there have been several retrospective reports suggesting an increase in seizures frequency post-cardiopulmonary bypass entailing increased patient morbidity [6]. A longstanding concern about cerebral injury potential in infants after heart surgery had been raised. The post-operative cognitive function evaluation of such patients has consistently demonstrated neurological impairment deficits, the etiology of which appears to be multifactorial and a growing need for better understanding is warranted. Variety of techniques had been used to gain insight into early neurological injury. Those techniques included electroencephalography brain isoenzymes and cerebral metabolism measurements. Brain imaging studies can also play a key role in mapping the extent and nature of the neurological insult [7]. The aim of this current work is to identify neurological complications within 30 days following pediatric cardiac interventions may it be through surgery or catheterization.

\section{Patients and Methods}

This study was a cross-section analytical study conducted at Cairo University Specialized Pediatric Hospital, Faculty of Medicine, in the period from January 
2015 to February 2016. The study included all pediatric cardiac patients who underwent cardiac interventions either by surgery or by catheter and developed neurological complications. The patients were recruited from the pediatric postoperative or post-catheterization ICU in Cairo University Specialized Pediatric Hospital. The neurological sequelae within 30 days of pediatric cardiac interventions were reported with exclusion of patients who presented with any neurological abnormality before the procedure or after 30 days of the cardiac interventions. Neurologically affected patients were subjected to (1) clinical evaluation; general examination, initial cardiac condition, type of cardiac intervention either by surgery or by catheter, neurological examination, (2) neuroimaging including CT/MRI, (3) neurophysiological studies including electroencephalography, visual evoked potential (for patients having abnormal gaze after intervention), and (4) cranial ultrasound. Follow-up after 3 months for the neurological sequelae: all patients were assessed clinically and MRI was done for patients who had normal CT brain at $1^{\text {st }}$ presentation. Informed verbal consent was taken and the study protocol was approved by the Research Committee of Pediatric Department, Faculty of Medicine, Cairo University (ref. number I.230314).

\section{Statistical methods}

Data were analyzed using SPSS(C Statistics version 17 (SPSS Statistics for Windows, Version 17.0. Chicago: SPSS Inc.). Normality of numerical data distribution was examined using the Shapiro-Wilk test. Normally distributed numerical variables were presented as mean \pm SD and intergroup differences were compared using the unpaired t-test (for two-group comparison). Categorical variables were presented as number and percentage and intergroup differences were compared using Fisher's exact test (for nominal data) or the Chi-squared test for linear-by-linear association (for ordinal data). Time to event analysis was done using the Kaplan-Meier method. All reported p-values are two tailed. $p<0.05$ was considered statistically significant.

\section{Results}

Our cohort included 1200 patients; 41 of them $(3.4 \%) ; 23$ males and 18 females developed neurological complications, the highest percentage was among open heart surgery group ( $n=19 / 167,11.4 \%$ ), followed by closed heart surgery group ( $n=10 / 138$, $7.2 \%$ ), the cardiac catheterization group ( $n=12 / 895$, $1.3 \%)$. The overall mortality was $110 / 1200(9.2 \%)$ with a significant difference between the three groups $(p<0.001)$ (Table 1). Regarding the diagnosis and type of cardiac intervention done of total 41 patients suffered from neurological complications 12 patients underwent interventional catherization, eight patients were acyanotic $(66.7 \%)$ while four patients were cyanotic $(33.3 \%)$ and the highest number of procedures done were balloon valvoplasty for PS for $5 / 12$ patients $(41.7 \%)$. Out of ten patients underwent closed heart surgery seven of them (70\%) were acyanotic while three patients $(30 \%)$ were cyanotic and the most frequent procedure done was Coarctectomy (4/10, 40\%). And finally, out of 19 patients who had open heart surgery 11 patients (57.9\%) were acyanotic and eight patients $(42.1 \%)$ were cyanotic and the most frequent procedure done was VSD closure $(5 / 19,26.4 \%)$ (Table 2).

Seizures were the most common presentation 38 of 41 patients $(92.6 \%)$ either in the form of focal fits $n=21 / 41(51.2 \%)$ or generalized fits in $15 / 41(36.6 \%)$ or myoclonic fits $2 / 41$ (4.9\%). Among these groups, 27 patients were controlled within $48 \mathrm{~h}(71.1 \%)$ in comparison to 11 patients $(28.9 \%)$ controlled after $48 \mathrm{~h}$ (Table 3 ). EEG was done for 24 patients presenting with seizures; 14 of them (58.3\%) had normal EEG findings while the remaining ten patients $(41.7 \%)$ had diffuse brain insult (Table 3). Among these 2 groups, five patients had normal brain imaging, 13 had brain infarction and six atrophic brain changes. There was no statistically significant correlation between brain imaging and ICU stay ( $p=$ 0.552). Four patients had abnormal eye movements post interventions with normal fundus examination in the four and two of them had abnormal VEP.

The neurological sequelae in the studied population were in the form of disturbed conscious level (DCL) in 2/41 (4.9\%), impaired motor function in 11/41 (26.8\%), impaired mental functions in 6/41(14.6\%), and hyperreflexia in 27/41 (65.9\%) (Table 3).

Regarding the early post-procedure motor assessment, there was no statistically significant difference between patients having normal motor function and impaired motor function regarding the occurrence of convulsions $(p=1.000)$. The mean for cardiopulmonary bypass time in patients with normal motor function was $110 \mathrm{~min}$ while those who have abnormal motor function was $81 \mathrm{~min}$ with $(p=0.295)$ and the mean for aortic clamping time for patients with normal motor function was 77 min while those who have abnormal motor function was 34 min with $(p=0.057)$.

Table 1: Comparison of the incidence of neurological complications associated with the cardiac interventions and the outcome

\begin{tabular}{llllll}
\hline Procedure & $\begin{array}{l}\text { Total number of } \\
\text { procedures }\end{array}$ & $\begin{array}{l}\text { Neurological } \\
\text { complications }(\%)\end{array}$ & $\begin{array}{l}\text { No neurological } \\
\text { neurological }(\%)\end{array}$ & $\begin{array}{l}\text { Outcome died } \\
(\%)\end{array}$ & $\begin{array}{l}\text { Survived to hospital } \\
\text { discharge (\%) }\end{array}$ \\
\hline Catheterization & 895 & $12(1.3)$ & $883(98.7)$ & $39(4.4)$ & $856(95.6)$ \\
Closed heart surgery & 138 & $10(7.2)$ & $128(92.8)$ & $33(23.9)$ & $105(76.1)$ \\
Open heart surgery & 167 & $19(11.4)$ & $148(77.2)$ & $38(22)$ & $129(77.2)$ \\
Total & 1200 & $41(3.4)$ & $1159(96.6)$ & $110(9.1)$ & $1090(90.8)$ \\
\hline
\end{tabular}


Table 2: Characteristics, initial diagnosis and interventions of the studied groups

\begin{tabular}{ll}
\hline Variable & No/Percentage \\
\hline Total number of affected patients & 41 \\
Male & $23(56.1)$ \\
Female & $18(43.9)$ \\
Interventions done for affected groups & \\
Interventional cardiac catheterization $(n=12)$ & \\
Pulmonary Valvoplasty for PS & $5(41.7)$ \\
VSD device closure for VSD & $2(16.7)$ \\
PDA closure for PDA & $1(8.3)$ \\
Aortic valvoplasty for AS & $1(8.3)$ \\
RF ablation of atresia for PS & $1(8.3)$ \\
PDA stenting for Pulmonary atresia - d.TGA & $1(8.3)$ \\
Raskind procedure for TGA & $1(8.3)$ \\
Closed heartsurgery ( $n=10)$ & \\
Coarctectomy for coactation of aorta & $4(40)$ \\
Vascular ring repair for Double aortic arch & $1(10)$ \\
PA banding and PDA Closure for ASD - PDA & $2(20)$ \\
BT shunt for Fallot tetrology & $1(10)$ \\
PA banding for tricuspid atresia -malposition great vessels & $1(10)$ \\
PDA closure for PDA & $1(10)$ \\
Open heart surgery ( $\mathrm{n}=19)$ & \\
VSD closure for VSD & $5(26.4)$ \\
Total repair of Fallot tetralogy & $3(15.8)$ \\
ASD VSD repair for ASD-VSD & $2(10.5)$ \\
ASD closure for ASD & $1(5.3)$ \\
ASD\&PDA closure for ASD, PDA and mild PS & $1(5.3)$ \\
CAVC repair for CAVC & $1(5.3)$ \\
Atrial repair for Common atrium & $1(5.3)$ \\
Senning operation for d.TGA & $1(5.3)$ \\
PA banding for DORV-TGA & $1(5.3)$ \\
Glenn operation and PDA ligation for extreme Fallot's tetralogy and PDA & $1(5.3)$ \\
Pulmonary valvotomy for PS & $1(5.3)$ \\
Glenn and Septectomy for single ventricle & $1(5.3)$ \\
Number of antiepileptics used & \\
Nil & $3(7.3)$ \\
Single & $26(63.4)$ \\
Multiple & $12(29.3)$ \\
Outcome 3 month post procedure & \\
Normal motor & $17(41.4)$ \\
Affected motor & $3(7.3)$ \\
Died & $21(51.2)$ \\
\hline & \\
& \\
&
\end{tabular}

Table 3: Spectrum of neurological complications in the studied groups $(n=41)$

\begin{tabular}{|c|c|}
\hline Variable & Frequency $(\%)$ \\
\hline \multirow{2}{*}{\multicolumn{2}{|c|}{ Early neurological assessment of the affected children }} \\
\hline & Motor function \\
\hline Normal & $30(73.2)$ \\
\hline Impaired & $11(26.8)$ \\
\hline \multicolumn{2}{|l|}{ Mental function } \\
\hline Normal & $35(85.4)$ \\
\hline Impaired & $6(14.6)$ \\
\hline \multicolumn{2}{|l|}{ Tendon reflexes } \\
\hline Hyperreflexia & $27(65.9)$ \\
\hline Hyporeflexia & $5(12.2)$ \\
\hline Normal tendon reflexes & $9(21.9)$ \\
\hline Seizures & $38(92.7)$ \\
\hline Open heart surgery & $16 / 38(42.1)$ \\
\hline Closed heart surgery & $10 / 38(26.3)$ \\
\hline Catheterization & $12 / 38(31.5)$ \\
\hline \multicolumn{2}{|l|}{ Onset } \\
\hline Day 1 or 2 & $21(55.3)$ \\
\hline After day 2 & 17 (44.7) \\
\hline \multicolumn{2}{|l|}{ Type of convulsions } \\
\hline Generalized & $15 / 38(39.5)$ \\
\hline Focal & $21 / 38(55.2)$ \\
\hline Myoclonic & $2 / 38(5.2)$ \\
\hline Disturbed conscious level & $2 / 41(4.9)$ \\
\hline Electroencephalogram & 24 \\
\hline Normal & $14(58.3)$ \\
\hline Diffuse brain injury & $10(41.7)$ \\
\hline Brain imaging & 27 \\
\hline Normal & $5(18.5)$ \\
\hline Brain infarction & $15(55.6)$ \\
\hline Atrophic changes & $7(25.9)$ \\
\hline Fundus examination & 4 \\
\hline Normal & $4(100)$ \\
\hline Abnormal & 0 \\
\hline VEP & 4 \\
\hline Normal & $2(50)$ \\
\hline Abnormal & $2(50)$ \\
\hline
\end{tabular}

Assessment of the motor function of the patients after 3 months (total number 20 patients) (4 patients died outside the ICU) revealed normal motor development in 14 patients among this Group 1 patient had good contractility and 13 had fair contractility while patients who had delayed motor development were six patients two of them had good contractility and four patients had fair contractility with $(p=0.013)$. Furthermore, assessment of the same two groups regarding number of inotropic agents showed no statistically significant difference between patients having normal motor function and patients having impaired motor function after 3 months post-procedure regarding number of inotropic agents $(p=0.067)$ (Table 4$)$.

Regarding the relationship between the brain imaging and post-procedure myocardial contractility, of the five patients who had normal brain imaging two patients had good myocardial contractility, three had fair contractility while all who had brain infarction had fair contractility (total 15 patients) and finally out of those who had atrophic changes (seven patients) two patients had good contractility and five had fair contractility $(p=$ 0.037 ) (Figure 1) and among the three groups of the brain imaging results five patients had no inotropic support while were admitted in the ICU, seven patients were on single inotrope, 11 patients on two inotropes while four patients were on three inotropes with $(p=0.975)$.

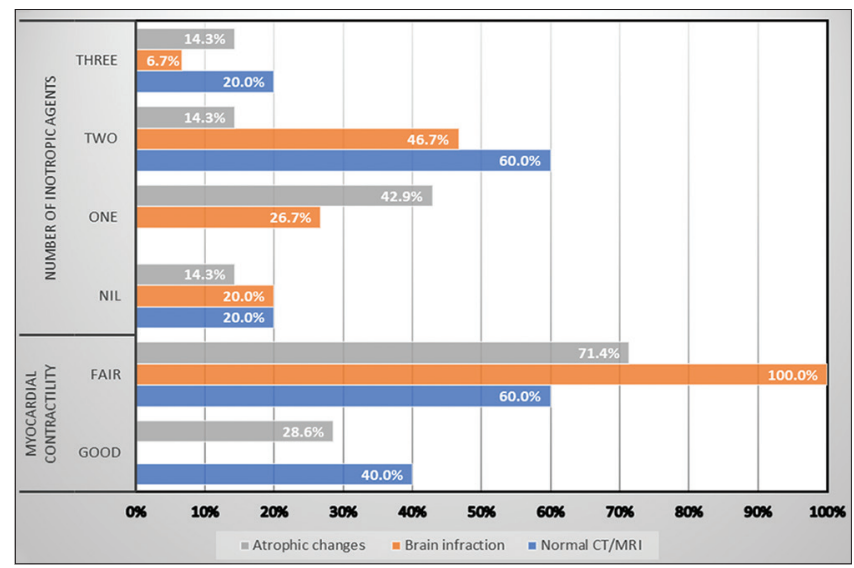

Figure 1: Relationship between CT/MRI findings and myocardial contractility in affected children $(p=0.037)$

\section{Discussion}

Congenital heart diseases (CHDs) have the highest incidence as congenital fetal malformations and are incriminated in causing a high rate of childhood mortality and morbidity [8].

The previous studies demonstrate that mortality from congenital heart disease (CHD) has been declining among infants and young children. There is little population-based data on behavior of CHD mortality among older children and adults [9].

Neurological complications are the most common long-term complication of congenital heart diseases in patients underwent surgery during infancy. Early surgical cardiac interventions, mainly in neonates 
Table 4: Relation between myocardial contractility, number of inotropes and outcome 3 months post-procedure in affected children

\begin{tabular}{|c|c|c|c|c|c|c|c|c|c|}
\hline \multirow[t]{3}{*}{ Variable } & \multicolumn{9}{|c|}{ Outcome 3 month post-procedure } \\
\hline & \multicolumn{2}{|c|}{ Normal motor function $(n=17)$} & \multicolumn{2}{|c|}{ Abnormal motor function $(n=3)$} & \multicolumn{2}{|c|}{$\operatorname{Died}(n=21)$} & \multirow[t]{2}{*}{$\chi^{2}$} & \multirow[t]{2}{*}{ Df } & \multirow[t]{2}{*}{$p$ value } \\
\hline & $n$ & $\%$ & $\mathrm{n}$ & $\%$ & $\mathrm{n}$ & $\%$ & & & \\
\hline \multicolumn{10}{|l|}{ Contractility } \\
\hline Good & 4 & 23.5 & 0 & 0 & 0 & 0 & 6.232 & 1.000 & 0.013 \\
\hline Fair & 13 & 76.5 & 3 & 100 & 20 & 95.2 & & & \\
\hline Poor & 0 & 0 & 0 & 0 & 1 & 4.8 & & & \\
\hline \multicolumn{10}{|l|}{ Number of inotropes } \\
\hline Nil & 4 & 23.5 & 0 & 0 & 2 & 9.5 & 3.348 & 1.000 & 0.067 \\
\hline One inotrope & 5 & 29.4 & 0 & 0 & 4 & 19 & & & \\
\hline Two inotropes & 6 & 35.3 & 2 & 66.7 & 9 & 42.9 & & & \\
\hline Three inotropes & 2 & 11.8 & 1 & 33.3 & 4 & 19 & & & \\
\hline Four inotropes & 0 & 0 & 0 & 0 & 2 & 9.5 & & & \\
\hline
\end{tabular}

and young children, increase the risk of brain injury. Abnormal neurological development experienced early in life has a long-term outcome [10].

Due to major developments in surgical procedures and per- and post-operative management, survival after neonatal cardiac surgery has risen to > 90 percent over the past decades. It has also become noticeable; however, that neurodevelopment is compromised in around one-third of children who underwent surgery in the neonatal period [11].

It is noteworthy to mention that among 1200 patients who underwent either catheterization procedures ( $n=895)$, closed heart surgery $(n=138)$, or open-heart surgery ( $n=167)$, and neurological complications occurred in 41 patients representing $3.4 \%$ of the studied population. Neurological complications were more common among patients subjected to open heart surgery, followed by closed heart surgery. The least common was patients subjected to cardiac catheterization. In our current work, 92.6\% (38/41) had seizures, half of them underwent open-heart surgery, and the least happened post-cardiac catheterization. The seizures were in the form of focal fits in 21 patients $(51.2 \%)$, generalized fits in 15 patients while myoclonic fits happened only in 2 patients. In accordance to our study, Liu et al. study [12] stated that out of 3,648 studied children $14(0.38 \%)$ of them developed neurological complications, $10 / 14(71.5 \%)$ patients had convulsions. On the other hand, Jafri et al. [13] in 2017 reported that 35 out 2000 patients (1.75\%) who underwent congenital heart disease surgery developed acute neurological complications and 28 of them (80\%) had seizures. In our cohort, the onset of convulsion was within the first 2 days after interventions in 21/38 patients $(55.3 \%)$, while its frequency was less than $3 /$ day in $31 / 38$ patients $(81.6 \%)$. Response to anticonvulsants varied, 27 patients were controlled within $48 \mathrm{~h}(71.1 \%)$ in comparison to $11(28.9 \%)$ controlled after $48 \mathrm{~h}$. Twenty-six patients $(68.4 \%)$ were controlled with one anticonvulsant, ten patients $(26.3 \%)$ with two anticonvulsants while only two patients needed three anticonvulsants (5.3\%). Similarly, Jafri et al. [13] study found that regarding response for anticonvulsants in his study three patients $(8.5 \%)$ needed no treatment, 19 patients were controlled on single drug (54\%) and 13 patients $(36 \%)$ needed multiple dug therapy to achieve control. The same study reported altered level of consciousness in five patients out of 35 (14\%) while our study reported altered level of consciousness in only $2 / 41(4.9 \%)$.

In the present study, 24 patients underwent electroencephalographic recordings, 14 cases had normal recording, diffuse brain injury was recorded in ten cases, hypoactive background activity in eight cases while abnormal focal discharge was found in two patients only.

In agreement to our study, Meyer et al. [14] studied the role of EEG recordings in children undergoing cardiac surgery. Sequential performance of 2 EEGs before and after cardiac surgery was done for 313 children (age: $54.2 \pm 55.7$ months). An abnormal EEG was detected in only eight of 313 patients $(2.5 \%$; focal slowing in one patient, generalized slowing in five patients, and epileptiform discharge in two patients) after cardiac surgery, while the EEG was normal in the remaining 305 patients $(97.5 \%)$.

Regarding post-procedure neurological assessment of the affected children $(n=41)$, motor function was impaired in 11 of them (26.8\%), in the form of paresis, while impaired sensorium occurred in six patients $(14.6 \%)$. Hyperreflexia was recorded in 27 patients $(65.9 \%)$, hyporeflexia in five patients $(12.2 \%)$. and normal tendon reflexes in 9 patients (21.9\%).

A study done by Asaki et al. [15] described the occurrence of arterial ischemic stroke before and after cardiac surgery, he found that out of 52 patients who developed AIS postoperatively 19 patients $(37 \%)$ developed facial or limb weakness.

In our current work, 27 out of 41 cases did brain imaging (CT or MRI). Fifteen patients had brain infarction (55.5\%), seven patients had atrophic changes (25.9\%), while five patients were normal.

Agarwal et al. [16] studied the occurrence of postoperative complications and association with outcomes in pediatric cardiac surgery, he found out of total of 325 patients were studied: 271 with CPB (cardiopulmonary bypass) and 54 without CPB, neurological complications occurred in 13/271(4.8\%) and $2 / 54(3.7 \%)$. He also found abnormal neuroimaging in $7 / 271(1.6 \%)$ and in $1 / 52(1.8 \%)$.

Similarly, Beca et al. [17] conducted his study on 153 infants who underwent surgery for congenital 
heart disease at $<8$ weeks of age. He assessed his patients with serial magnetic resonance imaging scans before and after surgery and at 3 months of age and found that out of 135 patients 59 infants (44\%) had new brain injury on their first post-operative scan (18 infants could not be assessed for early post-operative MRI imaging). Moreover, Peyvandi et al. [18] studied the development of new MRI findings in two groups of patients with HLHS $(n=30)$ and TGA $(n=49)$ who underwent open heart surgery with pre- and postoperative magnetic resonance. Post-operative MRI missing in three subjects with TGA and three subjects with HLHS due to death of subjects. He found a new MRI lesions postoperatively in the form of stoke in eight patients (one patient with TGA and seven patients with HLHS) and white matter lesions in 22 patients (13 with TGA and 9 with HLHS). In Andropoulos et al. [19], study, brain MRI was done for 67 neonates with cardiac surgery at 7 days postoperatively and at age 3-6 months. Twenty-four of 67 patients $(36 \%)$ had new postoperative white matter injury, infarction, or hemorrhage.

In our cohort, by comparing CT and MRI brain findings in the affected patients, there was no statistically significant difference between patients having normal EEG and those having abnormal EEG ( $p=0.109$ ).

However, in all the ten cases interpreted in EEG as diffuse brain insult, CT, or MRI always revealed a pathology; brain infarction in eight cases (85\%) and atrophic changes in the remaining two cases (20\%).

In the contrary, Rappaport et al. [20] studied the outcome of infants who have transient seizures after open heart surgery who underwent arterial switch operation for D-transposition of the great arteries correction. He found that transient postoperative clinical and EEG seizures were associated with MRI abnormalities at 1 year of age.

The current study showed that there was statistically significant correlation between CT and MRI findings and post-procedure myocardial contractility ( $p=0.037)$. However, there was no statistically significant correlation between CT and MRI findings and length of ICU stay ( $p=0.552)$.

In accordance to our work a previous study [17] found no statistically significant correlation between MRI findings and length of ICU stay ( $p=0.40)$.

Regarding ICU duration, it is evident from the results of the present study that there was statistically significant correlation between number of inotropic agents needed and ICU duration ( $p=0.002)$. These findings suggest that the long ICU stay was related to the severity of the cardiac condition and not to the severity of the neurological insult. On the contrary to our study Von Rhein et al. [21] who studied the risk factors for adverse neurodevelopmental outcomes in school-age children after full flow open-heart surgery for congenital heart disease in 117 children. He found that the neurological abnormalities at the follow-up examination were correlated with length of hospital stay $(p<0.001)$, and post-operative focal neurologic signs or EEG changes ( $p<0.001)$. He also found that poor motor function was associated with a greater number of bypass surgeries $(p<0.01)$.

This was in contrast to our study that found regarding the early motor function assessment there was absence of statistically significant difference between patients having normal motor function and abnormal motor function regarding by-pass time $(p=0.295)$ while there was near statistically significant difference between both groups regarding the aortic clamping time ( $p=$ 0.057 ). Furthermore, there was no statistical significant difference between patients having normal motor function and those having abnormal motor function regarding the occurrence of convulsions $(p=1.000)$.

The current study and the similar studies are targeting the patients having congenital heart diseases from the neurological point of view as they are suffering during their course of disease from several factors that can lead to neurological affection starting from chronic hypoxia, increased susceptibility to thrombosis, and intraoperative/intra catheterization insults.

Improving the neurological monitoring of these patients, early detection of hypoxic insults and methods that can detect early brain dysfunction like intraoperative EEG can maintain the normal future neurological development of these patients by providing early intervention to prevent catastrophic events like cerebral dehydrating measures intraoperatively or adding drugs with neuroprotective effects in the early course of the ICU.

Although this hard work our study has some limitations including, lacking of post-operative EEG and brain imaging in some patients due to bad general condition and early death of the patients before doing these investigations. Furthermore, lacking of the neurological evaluation preoperatively because most of the cardiac patients may have some sort of hypoxia which may lead to minor neurlogical affection which in this condition will not be related to the cardiac intervention done for these patients. And finally, the short duration of follow-up (only 3 months) which cannot predict the overall and long-term sequalae of the cardiac intervention.

\section{Recommendations of the current study}

1. Neurological assessment preoperatively for patient that will undergo cardiac interventions.

2. Neurological imaging (brain CT or MRI) preoperatively to help to identify new lesions after cardiac interventions.

3. Intraoperative monitoring of early brain insult and early postoperative by continues EEG monitoring.

4. Mass studies for these types of interventions with long-term follow-up till school age with IQ testing to detect any cognitive impairment. 


\section{Conclusion}

Neurological complications are the most common long-term complications after pediatric cardiac interventions and its early monitoring and management can improve the future neurodevelopmental outcome in infants and young children.

\section{Authors' Contributions}

Hala Mounir Agha Conception and design of the target clinical management criteria, critical review and final approval of the version to be published. Mai Mahmoud Hussien Data collection, clinical evaluation of patients, manuscript drafting; data interpretation. Marian Y. Girgis Data acquisition, clinical evaluation of patients; final approval of the version to be published. Omneya Gamal Eldin Afify Pediatric patient's selection, EEG interpretation, data interpretation; final approval of the version to be published

Mervat Ahmed Haroun Final approval of the version to be published profit sectors.

\section{References}

1. Kelly CJ, Arulkumaran S, Pereira CT, Cordero-Grande L, Hughes EJ, Teixeira RP, et al. Neuroimaging findings in newborns with congenital heart disease prior to surgery: An observational study. Arch Dis Childhood. 2019;104(11):1042-8. https://doi.org/10.1136/archdischild-2018-314822

PMid:31243012

2. Gamal AH, Ahmed EM, Ahmed IE, Omar SA. Postoperative complications in pediatric cardiac surgery patients done in a tertiary hospital. J Curr Med Res Pract. 2020;5(2):121.

3. Sutherasan $\mathrm{Y}$, Vargas M, Brunetti I, PPelosi. Ventilatory targets after cardiac arrest. Minerva Anestesiol. 2015;81(1):39-51. PMid:24642487

4. Gofton TE, Chu MW, Norton L, Fox SA, Chase L, Murkin JM, et al. A prospective observational study of seizures after cardiac surgery using continuous EEG monitoring. Neurocritical Care. 2014;21(2):220-7. https://doi.org/10.1007/s12028-014-9967-x PMid:24710654

5. Guo Z, Hu RJ, Zhu DM, Zhu ZQ, Zhang HB, Wang W. Usefulness of deep hypothermic circulatory arrest and regional cerebral perfusion in children. Ther Hypothermia Temp Manag. 2013;3(3):126-31. https://doi.org/10.1089/ther.2013.0006 PMid:24066266

6. Hsu CJ, Weng WC, Peng SS, Lee WT. Early-onset seizures are correlated with late-onset seizures in children with arterial ischemic stroke. Stroke. 2014;45(4):1161-3. https://doi. org/10.1161/strokeaha.113.004015 PMid:24595587

7. Mahle WT, Tavani F, Zimmerman RA, Nicolson SC, Galli KK,
Gaynor JW, et al. An MRI study of neurological injury before and after congenital heart surgery. Circulation. 2002;106(Suppl 12):I109-14.

PMid: 12354718

8. Silva KP, Rocha LA, Leslie AT, Guinsburg R, Silva CM, Nardozza LM, et al. Newborns with congenital heart diseases: Epidemiological data from a single reference center in Brazil. $J$ Prenat Med. 2014;8(1-2):11-6.

PMid:25332754

9. Gilboa SM, Salemi JL, Nembhard WN, Fixler DE, Correa A Mortality resulting from congenital heart disease among children and adults in the United States, 1999 to 2006. Circulation. 2010;122(22):2254-63. https://doi.org/10.1161/ circulationaha. 110.947002 PMid:21098447

10. Snookes SH, Gunn JK, Eldridge BJ, Donath SM, Hunt RW, Galea MP. A systematic review of motor and cognitive outcomes after early surgery for congenital heart disease. Pediatrics. 2010;125(4):e818-27. https://doi.org/10.1542/peds.2009-1959 PMid:20231182

11. Algra SO, Jansen NJ, van der Tweel I, Schouten AN, Groenendaal F, Toet M, et al. Neurological injury after neonatal cardiac surgery: A randomized, controlled trial of 2 perfusion techniques. Circulation. 2014;129(2):224-33. https://doi. org/10.1161/circulationaha.113.003312 PMid:24141323

12. Liu $X Y$, Wong $V$, Leung $M$. Neurologic complications due to catheterization. Pediatr Neurol. 2001;24(4):270-5. PMid:11377101

13. Jafri SK, Ehsan L, Abbas Q, Ali F, Chand P, UI Haque A. Frequency and outcome of acute neurologic complications after congenital heart disease surgery. J Pediatr Neurosci. 2017;12(4):328-31. https://doi.org/10.4103/jpn.jpn_87_17 PMid:29675070

14. Meyer S, Shamdeen MG, Shatat M, Schäfers HJ, Gortner L, Gottschling $S$, et al. The role of EEG recordings in children undergoing cardiac surgery for congenital heart disease. $J$ Pediatr Intensive Care. 2012;1(1):37-41. https://doi.org/10.3233/ pic-2012-007 PMid:31214383

15. Asakai H, Cardamone M, Hutchinson D, Stojanovski B, Galati JC, Cheung MM, et al. Arterial ischemic stroke in children with cardiac disease. Neurology. 2015;85(23):2053-9. https:// doi.org/10.1212/wnl.0000000000002036 PMid:26408496

16. Agarwal HS, Wolfram KB, Saville BR, Donahue BS, Bichell DP. Postoperative complications and association with outcomes in pediatric cardiac surgery. J Thorac Cardiovasc Surg. 2014;148(2):609-16. https://doi.org/10.1016/j.jtcvs.2013.10.031 PMid:24280709

17. Beca J, Gunn JK, Coleman L, Hope A, Reed PW, Hunt RW, et al. New white matter brain injury after infant heart surgery is associated with diagnostic group and the use of circulatory arrest. Circulation. 2013;127(9):971-9. https://doi.org/10.1161/ circulationaha.112.001089

PMid:23371931

18. Peyvandi S, Kim H, Lau J, Barkovich AJ, Campbell A, Miller S, et al. The association between cardiac physiology, acquired brain injury, and postnatal brain growth in critical congenital heart disease. J Thorac Cardiovasc Surg. 2018;155(1):291-300. https://doi.org/10.1016/j.jtcvs.2017.08.019 PMid:28918207

19. Andropoulos DB, Easley RB, Brady K, McKenzie ED, Heinle JS, Dickerson HA, et al. Changing expectations for neurological outcomes after the neonatal arterial switch operation. Ann 
Thorac Surg. 2012;94(4):1250-6. https://doi.org/10.1016/j. athoracsur.2012.04.050

PMid:22748448

20. Rappaport LA, Wypij D, Bellinger DC, Helmers SL, Holmes GL, Barnes PD, et al. Relation of seizures after cardiac surgery in early infancy to neurodevelopmental outcome. Circulation. 1998;97(8):773-9. https://doi.org/10.1161/01.cir.97.8.773

\section{PMid:9498541}

21. Von Rhein M, Dimitropoulos A, Buechel ER, Landolt MA, LatalB. Risk factors for neurodevelopmental impairments in school-age children after cardiac surgery with full-flow cardiopulmonary bypass. J Thorac Cardiovasc Surg. 2012;144(3):577-83. https:// doi.org/10.1016/j.jtcvs.2012.02.005

PMid:22405675 